\title{
Evaluation of a Parent Training Program for Promoting Filipino Young Children's Number Sense with Number Card Games
}

\author{
Sum Kwing Cheung* \\ Hong Kong Baptist University
}

\author{
Catherine McBride-Chang \\ The Chinese University of Hong Kong
}

\begin{abstract}
Not all parents are skilled in scaffolding their young children's numeracy learning. The present study investigated the effectiveness of a parent training program in promoting Filipino young children's number sense via card game playing at home. Participants were 161 young children and their parents; families were of a relatively low socioeconomic status. During the 10-week intervention period, parents in the experimental group received training on how to use number game cards to help their children acquire various numeracy concepts; parents in the control group received no special instructions. Children in the experimental group showed greater improvements in their performance on six number sense tasks (namely numeral identification, object counting, rote counting, missing number, numerical magnitude comparison, and addition) over the intervention period than did children in the control group. Findings of the present study suggest that providing simple training to parents on strategies for fostering their young children's number sense at home is important for giving children a good early start in basic number knowledge.
\end{abstract}

Keywords: card games, home numeracy experiences, number sense, parent training, young children

Home numeracy experiences play a vital role in children's number sense development (LeFevre, Polyzoi, Skwarchuk, Fast, \& Sowinski, 2010; LeFevre, Skwarchuk, Smith-Chant, Fast, Kamawar, \& Bisanz, 2009). However, not all parents recognize their important roles in fostering children's early numeracy development (Aubrey, Bottle, \& Godfrey, 2003; BlevinsKnabe \& Musun-Miller, 1998; Cannon \& Ginsburg, 2008; Evans \& Mansell, 2009). Moreover, some parents do not possess

* Corresponding Author: Sum Kwing Cheung, Assistant Professor, Early Childhood and Elementary Education Division, School of Continuing Education, Hong Kong Baptist University, 2/F, Franki Centre, 320 Junction Road, Kowloon Tong, Hong Kong. E-mail: skcheung@hkbu.edu.hk competence in promoting their young children's numeracy development during daily home activities (Ramani, Rowe, Eason, \& Leech, 2011; Skwarchuk, 2009). Therefore, the present study aimed to investigate the effectiveness of a parent training program for promoting Filipino young children's number sense at home with number card games.

\section{Children's Home Numeracy Experiences and Their Number Sense Development}

Ample empirical evidence (e.g., BlevinsKnabe \& Musun-Miller, 1996; Kleemans, Peeters, Segers, \& Verhoeven, 2012; LeFevre et al., 2009, 2010; Ramani et al., 2011) showed that there are positive correlations between children's 
home numeracy experiences and their number sense development. Blevins-Knabe and MusunMiller (1996), for example, found that parents' mention of number words and number facts to children had positive linkages with young children's performance in a standardized mathematics test. Similarly, LeFevre and her colleagues $(2009 ; 2010)$ demonstrated that parental reports of kindergarteners' involvement in numeracy activities at home, either formal or informal, were positively associated with children's numeracy competence. Ramani and her colleagues (2011) also showed that the more preschoolers participated in home numeracy activities (e.g., memorizing mathematics facts, learning simple sums, playing number card games), the better their early numeracy skills (e.g., identification of numerals, counting, and numerical magnitude comparison) were.

Despite the importance of home numeracy experiences, many children rarely engage in numeracy activities at home. In the study of Ramani and her colleagues (2011), almost half of the parents in this American sample reported that they never or almost never asked their preschool children to memorize mathematics facts. Moreover, $40 \%$ of parents in the sample stated that they never or almost never played number card games with their preschool children. Similarly, LeFevre and her colleagues (2010) found that about $20 \%$ of parents in their Canadian sample played number board and card games with their children only one to three times per month. About $10 \%$ of parents in the sample said that they never did so with their children.

Some parents lack the skills of scaffolding their young children's numeracy learning during joint numeracy activities at home. For instance, Vandermaas-Peeler, Ferretti, and Loving (2012) found that if training was not provided, parents seldom asked their preschool children to count aloud together with them when playing a board game that involved a collection of a specified number of items. In the study of Cheung (2013), when parents engaged their kindergarten children in playing a number board game that required players to move their tokens according to the number of dots obtained from the dice thrown, parents rarely incorporated extra numeracy components (e.g., teaching simple sums) during their interactions with children. Ramani and her colleagues (2011) also revealed that in their low-income sample, there were only a few numeracy-related exchanges (about 6.9\% of total utterances) during mothers' talk to their preschool children in number-related activities.

In view of the above, we explored the extent to which training of parents on strategies of supporting children's numeracy learning at home, in a low income section of $\mathrm{Cebu}$, in the Philippines, could foster their young children's number sense development.

\section{Effectiveness of Parent Training Programs in Promoting Children's Number Sense}

As revealed in several past studies, offering training programs to parents could empower them to scaffold their children's numeracy learning more effectively at home, and thus helped to promote children's number sense development. For example, in the study by Vandermaas-Peeler and colleagues (2012), parents in the experimental group received prompts from the experimenters about the numeracy components that could be incorporated into a board game; those in the control group did not. These parents in the experimental group were then found to display more numeracy guidance when playing the board game with their preschool children, and their children demonstrated better numeracy skills as compared to children in the control group. Starkey and Klein (2000) also found that when parents received training in effective instructional strategies of how to facilitate young children's learning of mathematics concepts, their children showed greater improvements in mathematical abilities than their peers in the control group over a four-month intervention period.

Though promising results were usually found among past studies on teaching parents numeracy guidance techniques, these training studies seldom used number card game playing as the context for promoting children's mastery 
of number concepts. This occurred perhaps because the ways of playing number game cards were often quite flexible; as a result, it might require more mental resources from parents to make number card game playing a fruitful learning experience. Therefore, the present study investigated whether low-income parents could be trained to use number card games to foster their young children's number sense development at home.

\section{Early School and Home Experiences of Children in the Philippines}

The Early Childhood Care and Development (ECCD) Act of 2000 states that kindergarten education is the foundation of basic education and all five-year-old children in the Philippines should receive kindergarten education (Department of Education, Republic of the Philippines, 2013). According to the $K$ to 12 Kindergarten Curriculum Guide, by age five, in terms of number concepts, Filipino children are expected to be able to identify and count the numerals up to 10 in daily life context, as well as to perform simple addition and subtraction up to 10 objects or pictures (Department of Education, Republic of the Philippines, 2013).

Statistics of UNESCO International Bureau of Education (2006), however, showed that in $2003 / 2004$, only $59.3 \%$ children entered primary education with previous preschool experience. Heaver and Hunt (1995) also raised out that there was a high dropout rate in early elementary school years and this might partially be attributed to children's poor school readiness.

The ECCD Act of 2000 also affirms that parents play an important role in children's early development as they were their first teachers (UNESCO International Bureau of Education, 2006). Nevertheless, poverty is a rather serious issue in the Philippines (Bihag-Boholano \& Puco, 2013). Among poor families, the amount of quality time parents can spend with their children was minimal and they are unlikely to provide an appropriate environment (e.g., an intellectually stimulating and emotionally supportive environment) for their children
(Bihag-Boholano \& Puco, 2013; Heaver \& Hunt, 1995; Manuel \& Gregorio, 2011). Their involvement in school was also very limited (Abulon, 2013; Heaver \& Hunt, 1995). It is therefore important and meaningful to equip parents in the Philippines with effective strategies of promoting children's intellectual development, including number sense development, at home.

From the above literature review, it could be concluded that the amount of children's home numeracy experiences tends to be predictive of children's early numeracy development. Given that parents do not always realize their important roles in and possess the essential skills of guiding their children's early numeracy development, a training program was provided to some Filipino low-income parents in the present study to promote their competence in fostering children's number sense with number card games at home; the primary aim of the present study was to test the effectiveness of the training program.

Number card game is chosen as the platform for promoting young children's number sense in our training program for various reasons. First, the fun and competitive nature of game playing can motivate young children to learn, practice and excel at the number sense skills (Booker, 2000). Second, number game cards often show concrete, visual representations of number concepts (e.g., numerals and the quantities they represented, the relations between numbers). Playing with number game cards thus allow young children to practice matching different representations of a number concept or solving abstract numeracy problems with the aid of concrete, visual representations (Booker, 2000). Last but not least, a wide variety of simple numeracy games can be developed based on a small and inexpensive deck of number game cards. This is in particular helpful for parents from low-income families because they might not be able to provide many educational toys and books for their children and grasp the opportunities to foster their children's number sense in daily life. 
To evaluate the extent to which the parent training program helped promote young children's number sense, a 2 (condition: experimental or control) $\times 2$ (session: pre-test or post-test) experimental design was adopted in the present study. Children's performance on six number sense tasks, including numeral identification, object counting, rote counting, missing number, numerical magnitude comparison, and addition, would be assessed at pre- and post-tests. These six number sense skills were selected as the focuses of the present study because they provide a full capture of the basic essence of number sense, i.e., the understanding of the meaning of numbers and number relationships (Malofeeva, Day, Saco, Young, \& Ciancio, 2004). Moreover, these number sense skills were often found to be benefited from simple parent-child joint numeracy activities among past studies (Cheung, 2013; Ramani et al., 2011; Vandermaas-Peeler et al., 2012).

Given the fact that young children can learn numeracy concepts from everyday activities at home and at daycare centres, we hypothesized that children in both the experimental and control groups would show significant improvements in their performances on the six number sense tasks described above over the 10 -week intervention period. However, as parents in the experimental group received training in how to promote their young children's number sense development with number card games at home, we hypothesized that compared to children in the control group, children whose parents participated in the training program (i.e., children in the experimental group) would show significantly greater improvements in their performance on the six numeracy tasks described above over the 10 -week intervention period.

\section{Method}

\section{Participants}

One hundred seventy-seven Filipino young children were recruited as participants from five daycare centers offering free classes in the Ermita District and Careta District in Cebu city, among the poorest districts in the area. As all centers were sponsored by the same non-governmental organization and followed similar curriculum, it could be assumed that the activities provided by the five daycare centers, including those related to numeracy, were comparable with each other. Sixteen children did not complete all the experimental tasks; and their data were removed from subsequent analyses. Thus, the final sample consisted of 161 Filipino young children ( 81 boys, 80 girls). Of them, 94 belonged to the experimental group and 67 belonged to the control group. Children's mean age at the time of pretest was 47.78 months ( $S D$ $=8.22$ months; ranged 19-80 months). Of children in the experimental group, 58 had their mothers received training, 19 had their fathers received training, 8 had both their mothers and fathers receiving training, and 9 had their other primary caregivers (grandmothers or aunts) received training. The mean age of parents of all children was 31.16 years $(S D=7.36$ years; ranged 18-56 years). The highest educational level attained by many of them was high school (61.4\%), followed by elementary school (23.5\%) and college (15.1\%). The daily salary of families ranged from Php0.00 (about USD0) to Php700.00 (about USD47.79), with a mean of Php228.09 (about USD15.57) and a standard deviation of Php96.75 (about USD6.61).

\section{Materials}

Two packs of game cards were used in the present study. One pack focused on the learning of numbers from 0 to 10 ; the other pack focused on the learning of numbers from 10 to 20 . In each pack, there were 44 number cards. For each number card, there was a set of animals on one side (except for the number card " 0 ") and a printed Arabic numeral that corresponded to the quantity of animals on the other side. Given that the set of animals sometimes contained more than one type of animals, the numbers of each type of animals in the set were also shown below the Arabic numeral in a smaller font size. Figure 

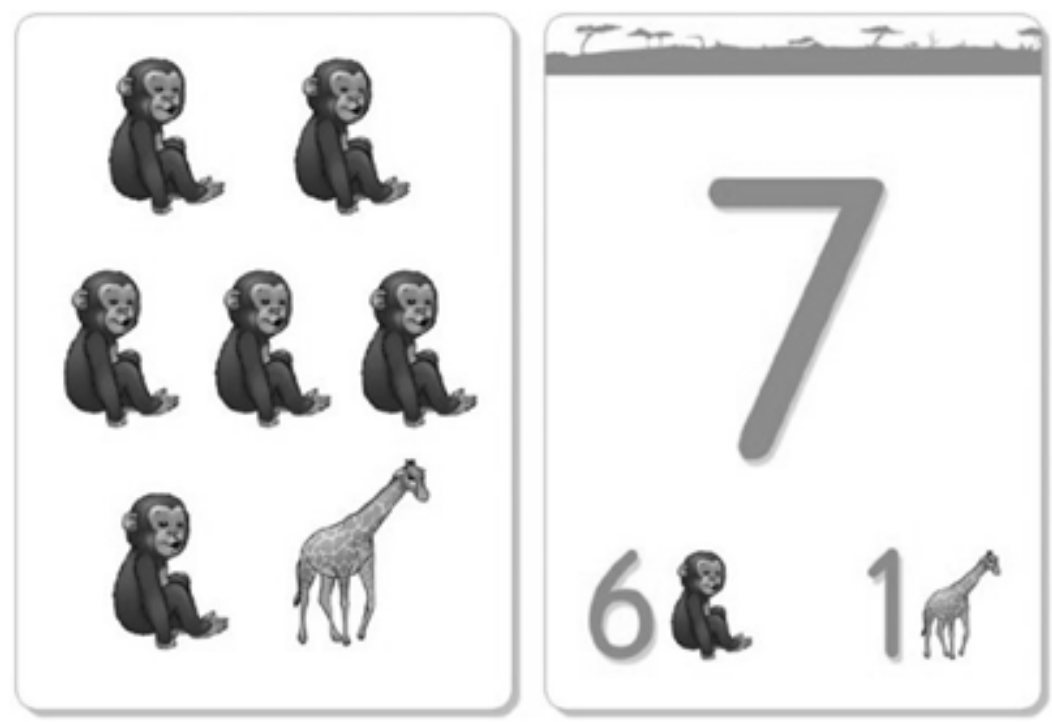

Figure 1. Sample of the two sides of a number game card used in the study.

1 shows a sample of the two sides of a number game card used in the present study. About 30 games were created based on the number cards.

\section{Measures}

Based on previous studies conducted in the West on young children's number sense (e.g., Bryant, Bryant, Gersten, Scammacca, \& Chavez, 2008; Clarke \& Shinn, 2004; Chard, Clarke, Baker, Otterstedt, Braun, \& Katz, 2005; Lago \& DiPerna, 2005; Ramani \& Siegler, 2008), six number sense tasks were developed for the Filipino context and were administered to children at both pre-test and post-test. Though the game cards used in the present study only involved numbers from 0 to 20 , the numbers involved in the number sense tasks were sometimes larger than 20 and smaller than 100 . This was because children might generalize the rules of how to solve number problems (e.g., numeral identification, number sequence recitation, numerical magnitude comparison, and addition) within 20 to other two-digit numbers up to 99.

Numeral identification. This task consisted of two practice items and 25 test items. Children were presented a sheet with a list of printed Arabic numerals, and they were asked to orally identify each of them. Of the test items, nine were one-digit numerals, and 16 were two-digit numerals between 10 and 99 (inclusive). A score was given for every correct answer, leading to a maximum score of 25. Cronbach's alphas of this task were .88 at pre-test and .90 at post-test.

Object counting. This task consisted of two practice items and 14 test items. In each trial, children were presented with a sheet with a set of animals, and they were instructed to count aloud the animals by ones. Upon completion, they were orally asked to identify the total number of animals in the set. Of the test items, 10 had animals arranged linearly in rows, three had animals arranged in a circular manner, and one had animals arranged in a random manner. The number of animals in the test items ranged from 4 to 20 (inclusive). A score was given for every correct answer, leading to a maximum score of 14. Cronbach's alphas of this task were .92 at pre-test and .90 at post-test.

Rote counting. This task consisted of one 
practice item and four test items. In each trial, children were orally asked to count forward from a given number to another given number by ones (e.g., from 1 to 10). Each test item involved 9 numbers (excluding the start number provided by the test administrator), and the numbers involved in the test items ranged from 1 to 33 (inclusive). For each test item, a score was given for every correct number counted in sequence, leading to a maximum score of 36 across the four test items. Cronbach's alphas of this task were .52 at pre-test and .82 at post-test.

Missing number. This task consisted of three practice items and 12 test items. In each trial, children were presented with a sheet with a string of three consecutive numbers. One of the three numbers in the string, was missing (e.g., 4, 5 , _ _ ), and children were required to orally identify the missing number. Of the test items, one-third had a missing number in the first place, another one-third had a missing number in the middle place, and the remaining one-third had a missing number in the last place. The missing numbers involved in the test items ranged from 2 to 23. A score was given for every correct answer, leading to a maximum score of 12 . Cronbach's alphas of this task were .89 at pre-test and .90 at post-test.

Numerical magnitude comparison. This task consisted of two practice items and ten test items. In each trial, children were presented with a sheet with two printed Arabic numerals, and they were required to point to the numeral that stood for a larger numerical value. The numerals involved in comparison ranged from 1 to 42 (inclusive). A score was given for every correct answer, leading to a maximum score of 10 . Cronbach's alphas were .91 at pre-test and .84 at post-test.

Addition. This task consisted of one practice item and six test items. In each trial, children were orally presented an addition fact, and they were required to tell the answer to the test administrator. The test items involved the sum of two one-digit numbers, and the answers of the test items ranged from 3 to 13. A score was given for every correct answer, leading to a maximum score of 6 . Cronbach's alphas of this task were .85 at pre-test and .89 at post-test.

\section{Procedure}

Informed consent was first sought from parents. Children whose parents agreed to participate in the present study were then pre-tested individually on six number sense tasks at their home.

During the 10-week intervention period, for each child in the experimental group, a coach conducted three home visits (a total of two and a half hours) per week. All coaches got a bachelor degree in education or related disciplines and had received training in child behavior management. Each time, the coach began by playing with the child in front of the parent, followed by the parent playing with the child with the help of the coach. Before the end of the visit, the parent was given a small assignment, i.e., games to be played with the child on the days that the coach did not visit the home.

Immediately after the intervention period, children in both the experimental and control groups were post-tested individually on the six number sense tasks at their home.

\section{Results}

\section{Preliminary Analyses}

First, to understand the relations of children's performance on the six number sense tasks, namely numeral identification, object counting, rote counting, missing number, numerical magnitude comparison, and addition, bivariate correlation analyses were conducted. Table 1 shows the correlations among children's performance on the six number sense tasks at pre-test and post-test. As shown in Table 1, the correlations were always moderate to high $(\gamma \mathrm{s}$ ranged from .51 to .78 at pre-test and from .64 . to .82 at post-test, all $p \mathrm{~s}<.001)$.

Next, to ensure that there was no bias in the 
Table 1

Correlations among Children's Performance on Number Sense Tasks

\begin{tabular}{lcccccc}
\hline \multicolumn{1}{c}{ Number Sense Task } & 1 & 2 & 3 & 4 & 5 & 6 \\
\hline 1. Numeral Identification & - & $.59^{* * *}$ & $.58^{* * *}$ & $.65^{* * *}$ & $.51^{* * *}$ & $.63^{* * *}$ \\
2. Object Counting & $.75^{* * *}$ & - & $.78^{* * *}$ & $.58^{* * *}$ & $.58^{* * *}$ & $.54^{* * *}$ \\
3. Rote Counting & $.70^{* * *}$ & $.75^{* * *}$ & - & $.63^{* * *}$ & $.68^{* * *}$ & $.58^{* * *}$ \\
4. Missing Number & $.82^{* * *}$ & $.78^{* * *}$ & $.64^{* * *}$ & - & $.67^{* * *}$ & $.58^{* * *}$ \\
6. Numerical Magnitude Comparison & $.78^{* * *}$ & $.78^{* * *}$ & $.65^{* * *}$ & $.83^{* * *}$ & - & $.61^{* * *}$ \\
7. Addition & $.78^{* * *}$ & $.79^{* * *}$ & $.74^{* * *}$ & $.76^{* * *}$ & $.79^{* * *}$ & - \\
\hline
\end{tabular}

$N=161$. Values obtained from pre-test were presented above the diagonal; values obtained from post-test were presented below the diagonal.

$* * * p<.001$

assignment of children into the experimental and control groups, six independent $t$-tests were performed to compare pre-test scores between the two groups on the six number sense tasks aforementioned. Results indicated that children in the experimental and control groups did not differ in their performances on the six number sense tasks at pre-test (all $p \mathrm{~s}>.05$ ).

Last, preliminary analyses revealed that there were positive correlations between children's age and their performance on the six number tasks at pre-test ( $\gamma \mathrm{s}$ ranged from .19 to .32 , all $p$ s $<.05$ ) but boys and girls did not vary in their pre-test scores on all six number sense tasks (all $p s>.05)$. There were no age and sex differences in the effects on the parent training program on children's performance on the six number sense tasks (all $p \mathrm{~s}>.05$ ); data were therefore collapsed across age groups and sex in subsequent statistical analyses.

\section{Effects of the Parent Training Program on Promoting Children's Number Sense}

Children's improvement in number sense over time was examined in two ways: repeated measures analyses and paired-sample $t$-tests. Table 2 showed the means and standard deviations of children's performance on the six number sense tasks at pre-test and post-test in the experimental and control groups.

First, to examine whether children's improvement in number sense over the 10 -week intervention period varied across the two groups, six separate 2 (condition: experimental or control) $\times 2$ (session: pre-test or post-test) repeated measures analyses were performed on the six number sense tasks mentioned above, with age entered as covariate. Significant interaction effects emerged for all of them: the numeral identification task, $F(1,158)=87.19, p<.001$; the object counting task, $F(1,158)=50.03, p$ $<.001$; the rote counting task, $F(1,158)=33.31$, $p<.001$; the missing number task, $F(1,158)=$ $82.85, p<.001$; the numerical magnitude comparison task, $F(1,158)=52.73, p<.001$; and the addition task, $F(1,158)=91.95, p<.001$. Age was not a significant covariate for all six number sense tasks (all $p s>.05$ ).

To further test whether children of each group showed significant improvements in number sense across time, six separate paired-sample $t$-tests were conducted to compare the gains from pretest to posttest on each of the six number sense tasks for each of the two groups. Results showed that children in the experimental group showed significant improvements in their performances on all six number sense tasks over the intervention period: the numeral identification task, $t(93)=18.72, p<.001$; the object counting task, $t(93)=15.18, p<.001$; the rote counting task, $t(93)=11.39, p<.001$; the missing number task, $t(93)=13.76, p<.001$; the numerical magnitude comparison task, $t(93)=$ 
Cheung \& McBride-Chang

Table 2

Means and Standard Deviations (in parenthesis) of Children's Performance on Number Sense Tasks at Pre-test and Post-test in the Experimental and Control Groups

\begin{tabular}{lccccc}
\hline \multirow{2}{*}{ Number Sense Task (Max. Score) } & \multicolumn{2}{c}{ Experimental $(n=94)$} & & \multicolumn{2}{c}{ Control $(n=67)$} \\
\cline { 2 - 3 } \cline { 5 - 6 } & Pre-test & Post-test & & Pre-test & Post-test \\
\hline \multirow{2}{*}{ Numeral Identification (20) } & 1.13 & 7.73 & & 1.15 & 3.31 \\
& $(2.30)$ & $(3.36)$ & & $(2.68)$ & $(3.03)$ \\
Object Counting (14) & 2.61 & 8.54 & & 3.15 & 4.94 \\
& $(3.32)$ & $(2.97)$ & & $(4.30)$ & $(3.27)$ \\
Rote Counting (36) & 4.11 & 14.33 & & 5.07 & 8.46 \\
& $(5.22)$ & $(8.88)$ & & $(6.63)$ & $(5.37)$ \\
Missing Number (12) & .32 & 4.77 & & .78 & 1.30 \\
& $(1.22)$ & $(3.11)$ & & $(1.98)$ & $(2.30)$ \\
Numerical Magnitude Comparison (10) & 1.21 & 5.32 & & 1.85 & 2.51 \\
& $(2.39)$ & $(2.45)$ & & $(2.91)$ & $(2.10)$ \\
Addition (6) & .31 & 3.47 & .48 & 1.09 \\
& $(.87)$ & $(2.06)$ & & $(1.33)$ & $(1.40)$ \\
\hline
\end{tabular}

$13.12, p<.001$; and the addition task, $t(93)=$ $15.35, p<.001$. On other hand, children in the control group showed significant improvements in their performance on only five number sense tasks over the intervention period: the numeral identification task, $t(66)=8.16, p<.001$; the object counting task, $t(66)=4.17, p<.001$; the rote counting task, $t(66)=5.56, p<.001$; the missing number task, $t(66)=2.22, p<.05$; and the addition task, $t(66)=5.01, p<.001$. There was no significant difference in the performance of children in the control group on the numerical magnitude comparison task between pre-test and post-test, $t(66)=1.86, p>.05$.

In order to determine the sizes of the effects of the parent training program on children's number sense, Cohen's $d$ s were calculated. Results showed that the effect sizes were quite large, as follows: For the numeral identification task, $d=1.55$; for the object counting task, $d=$ 1.20 ; for the rote counting task, $d=1.01$; for the missing number task, $d=1.73$; for the numerical magnitude comparison task, $d=1.40$; and for the addition task, $d=1.71$.

\section{Discussion}

The present study tested the effectiveness of a parent training program in promoting young children's number sense via number card game playing at home. Our findings suggested that children whose parents received training (i.e., the experimental group) showed significantly greater improvements in their performance on six number sense tasks over the 10-week intervention period than children whose parents did not receive any training (i.e., the control group); the effect sizes of the parent training program were quite large.

Consistent with our hypotheses, children in the control group performed significantly better on five out of six number sense tasks under investigation at post-test as compared to pre-test. These tasks included numeral identification, object counting, rote counting, missing number, and addition. The only task that children in the control group did not vary on in their performance over time was the numerical magnitude comparison task. This happened perhaps because parents tend to focus less on teaching their preschool children "comparing" as compared to other types of numeracy skills (e.g., 
"counting objects," "reciting numerals," "reading numerals to 20 " and "adding objects") during everyday activities (Skwarchuk, 2009).

In contrast, also in line with our hypotheses, children in the experimental group demonstrated gains in all six number sense skills from pre-test to post-test; and such gains were much more marked than those displayed by children in the control group. In other words, the parent training program developed in the present study was effective in promoting Filipino young children's number sense. To account for the positive effects brought by the parent training program, several explanations could be put forward. First, the training program might promote parents' understanding of the wide array of numeracy contents (e.g., counting objects, numerical magnitude comparison, simple addition) that could be introduced during number card game playing; as a result, children could show improvements in various domains of number sense. In addition, during the home visits by the coaches, parents were provided with some concrete examples of the games that could be played with the number cards. This was particularly helpful for parents of a low educational level, as they might not be able to think of many interesting ways of playing the number cards. Finally, when the coaches demonstrated how to play number card games with children in front of the parents during home visits, parents could observe and imitate the effective instructional strategies displayed by the coaches in real contexts. This could help minimize the potential difficulties faced by parents in transferring the numeracy guidance techniques learned into new contexts.

Findings of the present study have several implications. First, the present study demonstrated that home numeracy experiences are crucial for children's number sense development. The findings can highlight for parents the importance of providing their young children exposure to numeracy concepts at home, as parents tended to value their young children's language and literacy learning more than their numeracy learning (Blevins-Knabe \& Musun-Miller, 1998). Second, the present study showed that parent-child number card game playing is a useful home numeracy activity for promoting young children's number sense development, as it provides a fun context for children to acquire numeracy concepts and practice related skills. Finally, the present study provided further empirical support to the notion in the existing literature (e.g., Cheung, 2013; Vandermaas-Peeler et al., 2012) that parents can be trained to provide effective home learning environment for young children's number sense development. According to the social constructivist view of learning (e.g., Rogoff, 1990), children learn by interacting with more competent members in the society. Parents are therefore important agents of children's socialization. It is therefore necessary to provide training to parents on how to foster their young children's numeracy learning at home, as not all parents possess such competence. Examples of the training contents include effective interactive techniques during numeracy guidance and skills of adjusting the difficulty level of the numeracy-related exchanges based on their children's abilities. The benefits brought by such kind of parent training may especially be salient among children from underprivileged families (e.g., those in our sample) because their parents often lack the knowledge, skills and resources to provide stimulating home environments for children's intellectual development (BihagBoholano \& Puco, 2013; Heaver \& Hunt, 1995; Manuel \& Gregorio, 2011). By empowering parents to support children's learning at home, children's gains from the intervention can become more sustainable, and the potentials of these children are more likely to be actualized.

Nevertheless, there were limitations of the present study. First, the present study included only one experimental group and one control group. Compared to parents in the experimental group, parents in the control group received neither training nor game cards from the researchers. Thus, it is difficult to know whether the positive effects observed in the experimental group came from number card game playing, the parent training provided by the coaches, or a combination of both. Thus, in future studies of a 
similar nature, it would be better to have three groups in the experimental design: one group with the game provided, one group with the game and the parent training provided, and one group with no materials provided. In addition, the present study only investigated the effects of the parent training program on children's number sense. Future studies can explore other potential benefits brought by parent training programs of this kind (e.g., children's interest in numeracy learning, the quality of parent-child relationships). The relations of parents' feelings about mathematics and attitudes towards early numeracy learning to the effectiveness of parent training programs can also be investigated.

Despite these limitations, however, the present study demonstrated the effectiveness of a simple program for promoting young lower income Filipino children's number sense very early. In the present study, parents played important roles in children's early number sense development. However, around the world, parents vary greatly in their abilities to provide high-quality home numeracy experiences for their young children. Therefore, it is important to train parents on how to create stimulating home environments for the promotion of young children's numeracy learning.

Acknowledgements: The study was funded by the Arcanys Early Learning Foundation.

\section{References}

Abulon, E. L. R. (2013). Barangay day care centers: Emergence, current status and implications to teacher education. Proceeding of the Global Summit on Education 2013. Retrieved from http://worldconferences.net /proceedings/gse2013/papers_gse2013/094\% 20Edna \% 20Luz\%20R.\%20Abulon.pdf

Aubrey, C., Bottle, G., \& Godfrey, R. (2003). Early mathematics in the home and out-of-home contexts. International Journal of Early Years Education, 11, 91-103. doi: 10.1080/0966976032000116158

Bihag-Boholano, H., \& Puco, M. L. C. G. (2013).
Reaching the unreached: A challenge for Filipino educators. International Forum, 16, 51-66.

Blevins-Knabe, B., \& Musun-Miller, L. (1996). Number use at home by children and their parents and its relationship to early mathematical performance. Early Development and Parenting, 5, 35-45. doi: 10.1002/ (SICI)1099-0917(199603)5:1<35::AID-EDP1 13>3.0.CO;2-0

Blevins-Knabe, B., \& Musun-Miller, L. (1998). Adults' beliefs about children and mathematics: How important is it and how do children learn about it? Early Development and Parenting, 7, 191-202.

doi:10.1002/(sici)1099-0917(199812)7:4<191 ::aid-edp181>3.0.co;2-i

Booker, G. (2000). The maths game: Using instructional games to teach mathematics. Wellington, N. Z.: New Zealand Council for Educational Research.

Bryant, D., Bryant, B., Gersten, R., Scammacca, N., \& Chavez, M. (2008). Mathematics intervention for first-and second-grade students with mathematics difficulties: The effects of tier 2 intervention delivered as booster lessons. Remedial and Special Education, 29, 20-32. doi: 10.1177/ 0741932507309712

Cannon, J., \& Ginsburg, H. P. (2008). "Doing the math": Maternal beliefs about early mathematics versus language learning. Early Education and Development, 19, 238-260. doi: 10.1080/10409280801963913

Chard, D. J., Clarke, B., Baker, S., Otterstedt, J., Braun, D., \& Katz, R. (2005). Using measures of number sense to screen for difficulties in mathematics: Preliminary findings. Assessment for Effective Intervention, 30, 3-14. doi: 10.1177/073724770503000202

Cheung, S. K. (2013). Maximizing the educational benefits of parent-child number board game playing to kindergarteners: The importance of parent training. Poster presented at the Biennial Meeting of the Society for Research in Child Development, Seattle, Washington.

Clarke, B., \& Shinn, M. R. (2004). A preliminary 
investigation into the identification and development of early mathematics curriculumbased measurement. School Psychology Review, 33, 234-238.

Department of Education, Republic of the Philippines (2013). Standards and competencies for five-year old Filipino children. Retrieved from http://www.deped. gov.ph/sites/default/ files/page/2014/Final\%20Kindergarten $\% 20 \mathrm{C}$ G\%20December\%202013.pdf

Evans, M. A., \& Mansell, J. V. (2009). Parents as teachers of reading, not mathematics. Paper presented at the Biennial Meeting of the Society for Research in Child Development, Denver, Colorado.

Heaver, R. A., \& Hunt, J. M. (1995). Improving early childhood development: An integrated program for the Philippines. Washington, D.C.: World Bank and the Asian Development Bank.

Kleemans, T., Peeters, M., Segers, E., \& Verhoeven, L. (2012). Child and home predictors of early numeracy skills in kindergarten. Early Childhood Research Quarterly, 27, 471-477. doi: 10.1016/ j.ecresq.2011.12.004

Lago, R. M., \& DiPerna, J. C. (2010). Number sense in kindergarten: A factor-analytic study of the construct. School Psychology Review, 39, 164-180.

LeFevre, J. , Polyzoi, E., Skwarchuk, S. L., Fast, L., \& Sowinski, C. (2010). Do home numeracy and literacy practices of Greek and Canadian parents predict the numeracy skills of kindergarten children? International Journal of Early Years Education, 18, 55-70. doi: 10.1080/09669761003693926

LeFevre, J., Skwarchuk, S. L., Smith-Chant, B. L., Fast, L., Kamawar, D., \& Bisanz, J. (2009). Home numeracy experiences and children's math performance in the early school years. Canadian Journal of Behavioural Science, 41, 55-66. doi: 10.1037/a0014532

Malofeeva, E., Day, J., Saco, X., Young, L., \& Ciancio, D. (2004). Construction and evaluation of a number sense test with head start children. Journal of Educational Psychology, 96, 648-659. doi:10.1037/
0022-0663.96.4.648

Manuel, M. F., \& Gregorio, E. B. (2011). Legal frameworks for early childhood governance in the Philippines. International Journal of Child Care and Education Policy, 5, 65-76.

Ramani, G. B., Rowe, M. L., Eason, S. H., \& Leech, K. A. (2011). Count on it? Math talk during parent-child interactions in Head Start families. Poster presented at the Biennial Meeting of the Cognitive Development Society, Philadelphia, PA.

Ramani, G. B., \& Siegler, R. S. (2008). Promoting broad and stable improvements in low-income children's numerical knowledge through playing number board games. Child Development, 79, 375-394. doi:10.1111/ j.1467-8624.2007. 01131.x

Rogoff, B. (1990). Apprenticeship in thinking: Cognitive development in social context. Oxford, England: Oxford University Press.

Skwarchuk, S. (2009). How do parents support preschoolers' numeracy learning experiences at home? Early Childhood Education Journal, 37, 189-197. doi: 10.1007/s10643-009-0340-1

Starkey, P., \& Klein, A. (2000). Fostering parental support for children's mathematical development: An intervention with Head Start families. Early Education and Development, 11, 659-680. doi:10.1207/s15566935eed1105 7

UNĒESCO International Bureau of Education (2006). Philippines: Early childhood care and education (ECCE) programmes. Country Profile commissioned for the EFA Global Monitoring Report 2007, Strong foundations: Early childhood care and education. Retrieved from http://unesdoc.unesco.org/ images/0014/001472/147225e.pdf

Vandermaas-Peeler, M., Ferretti, L., \& Loving, S. (2012). Playing The Ladybug Game: Parent guidance of young children's numeracy activities. Early Child Development and Care, 10, 1289-1307. doi:10.1080/03004430. 2011.609617

Received January 1, 2015

Revision Received January 30, 2015 Accepted February 4, 2015 